\title{
Promoting Teaching in Rural Schools
}

\author{
Edwin G. Ralph \\ University of Saskatchewan
}

\begin{abstract}
This study extends previous investigations of interns' and their cooperating teachers' views of teaching in rural schools, which were conducted in 1998, 1999, 2000, and 2001. The present paper includes findings from a survey conducted in 2002 of a fifth cohort of interns and their classroom cooperating teachers. It examined the same four items analyzed in the four previous studies (namely: the advantages of teaching in rural areas, the disadvantages of doing so, recommendations about practicum placements for future interns, and advice for these interns), as well as items that also solicited respondents' views of what the University's College of Education and the rural school divisions could do to promote both interning and teaching in rural schools. Findings are synthesized and implications are drawn for both the University and the school divisions involved in these studies as well as for other institutions in similar situations-with respect to improving internship and teaching, and to helping promote the stability of rural communities, of which the school is often a key component.
\end{abstract}

\section{Introduction}

In recent years, Canada's three Prairie provinces have witnessed increased urbanization, substantial governmental financial cutbacks, economic downturns in the agricultural and related sectors, and the consequent decline in rural populations. As a result, school districts in these provinces have been forced to keep pace with these changes by making such adjustments as the creation of multi-grade classrooms, the closing of small rural schools, the re-alignment of school bus routes, the incorporation of itinerant staff-assignments, and the amalgamation of rural school divisions ("Government Encourages," 2001; Saskatchewan Learning, 2001, 2002; Ralph, 2002).

However, even though rural school enrolments are declining (Saskatchewan Learning, 2001, 2002) there will still be a number of teachers required to teach in schools in these rural areas. This ongoing need to hire teachers will be amplified even more within the next few years because of three key factors that have emerged in the Prairie Provinces: a number of veteran teachers will reach retirement age and will need to be replaced; the number of students entering

Edwin Ralph is a Professor and the Graduate Chair in the Department of Curriculum Studies in the College of Education at the University of Saskatchewan in Saskatoon. 
teacher education institutions has not increased substantially; and many graduating teachers will seek to secure teaching positions in larger metropolitan centres rather than in rural areas, thus leading to a possible scarcity of teachers for the latter. Therefore, it is in the best interests of rural school divisions and teacher education faculties to encourage beginning teachers to apply for teaching positions outside of the metropolitan areas.

The two-fold purpose of this study is: (a) to examine the advantages and disadvantages that teachers (both neophyte and experienced) perceive with respect to teaching in rural settings, and (b) to draw implications from these findings for teacher education institutions and rural school divisions, as they seek to promote rural teaching.

\section{Previous Research}

In one study, Borys et al. (1991) reported nine benefits accruing to rural school divisions, to the faculty of education, and to practicum students, as a result of participating in a collaborative school-university partnership that jointly delivered an effective practicum program. Three key benefits were: (a) student teachers received bursary support and assistance in finding housing in their placement; (b) faculty supervisors and classroom cooperating teachers shared the supervisory responsibility — and received the consequent recognition and support - for collaborating in helping the students to develop professionally; and (c) the school division capitalized on this collaboratively - conducted practicum to recruit new teachers for its schools.

In another study, Hemmings and Boylan (1992) surveyed 23 second year student teachers who did a three-week practicum in remote rural schools in Australia. The findings showed that participants were generally positive about both their teaching and living experiences, and that they would be willing to teach later in similar locations.

A third study also conducted in Australia (Meiklejohn \& Barrett, 1994) indicated that novice teachers in rural communities: (a) recognized the importance of the school to the life of the community; (b) saw that rural schools vary as to the quantity of resources available to provide effective education; (c) understood the key role that teachers fill in rural settings; and (d) witnessed the close relationships that develop between rural teachers and their students.

In a recent study of teacher interns doing their extended practicum in rural schools in Saskatchewan, Ralph $(2001,2002)$ found that many of the advantages and disadvantages of rural teaching cited by the interns were no different from those expressed by urban interns. Most of the concerns identified were common to all beginning teachers regardless of their placement, and these concerns typically reflected novice teachers' three types of concern revealed in previous research on beginning teachers' experiences (Fuller \& Bown, 1975; Piland \& Anglin, 1993; Ralph, 2002; Smith \& Sanche, 1992, 1993). These researchers suggested that the concerns followed a developmental gradation forming three general stages: (a) concern for “self” (e.g., “Will the students like me?”); (b) concern for "task” (e.g., "Will I have effective classroom management?”); and 
(c) concern for "others” (e.g., "Will the pupils learn what I am teaching them?" (Wilson, Ireton, \& Wood, 1997).

The elements that Ralph (2002) identified as being distinct to teaching in rural schools in contrast to urban ones related largely to non-school factors, such as rural interns being able to secure suitable living accommodations for the 4-month practicum; interns incurring extra expenses for travel to and from the rural location during the practicum; or the lack of access to facilities providing a variety of instructional resources and/or cultural/leisure/entertainment venues compared to their easy access in the cities. Furthermore, informal observations and anecdotal evidence reported both by college supervisors and classroom cooperating teachers involved in practicum programs in rural Canadian schools attest to these findings (Ralph, 2000, 2001). However, systematic North American research addressing this area has been rather sketchy and unfocused ( Khattri, Riley, \& Kane, 1997).

Yet, this situation is changing, as shown by recent events that have emerged in the field, such as: (a) a general call for more widespread, serious research on preparing new teachers for rural teaching (Howley, 1997) and (b) the establishment and expansion of the annual Canadian National Congress on Rural Education inaugerated in 1996 (Saskatchewan Educational Leadership Unit, 2003).

The present study is an example of the type of research being spawned by the increasing interest among educators and community members to deal sensibly and sensitively with the current issues confronting rural education in the Western Canadian context.

\section{The Provincial Demographics}

The present study was conducted under the auspices of the College of Education at the University of Saskatchewan, one of the two university teacher education institutions in the province of Saskatchewan. Saskatchewan is the sixth largest of Canada's ten provinces in terms of population, having approximately one million people - about 200,000 of whom are students in the Province's K-12 school system.

Approximately 37\% of Saskatchewan's citizens live in rural areas, while the remainder reside in its 13 cities (i.e., urban centres, which have a population of 5,000 or more.) Sixty-two percent of the nearly $800 \mathrm{~K}-12$ schools in the province are located in rural areas (i.e., in towns, villages, hamlets or on aboriginal/band lands); and these rural schools enrol about $41 \%$ of the province's total student population. On the other hand, the cities have about $40 \%$ of the province's schools, but nearly $60 \%$ of the total student enrollment (Saskatchewan Learning, 1998, 2001, 2002).

\section{The Extended Practicum Program}

Each year the College of Education involved in the present study places approximately 400 teacher interns in provincial K-12 schools during their final year of their teacher education program. They are placed in urban and rural schools in the province in order to complete their four-month extended 
practicum, under the joint supervision of a classroom cooperating teacher and a college supervisor. Each faculty supervisor works with 20 to 25 pairs in a specific geographical location. (A "pair" consists of one extended practicum student and his/her classroom cooperating teacher.) With this arrangement, novice teachers develop their pedagogical and self-evaluatory skills benefiting from the mentorship of at least two experienced professionals within this triad framework (Howey \& Zimpher, 1989; Ralph, 1994).

Past placement statistics from the College indicate that approximately $54 \%$ of teacher interns each year do their extended practicum in urban schools and $46 \%$ are placed in rural schools. Also their three-week "pre-internship" student teaching practica are completed as follows: approximately $32 \%$ of student teachers are placed in rural schools and 68\% in urban schools.

\section{Method}

\section{Subjects}

Five cohorts of teacher interns who did their extended practicum in rural schools under the supervisory jurisdiction of the author in the fall semester in each of 1998, 1999, 2000, 2001, and 2002 completed written questionnaires that solicited their views on their rural internship experiences. Their classroom cooperating teachers completed similar questionnaires on their rural teaching experiences. In total, the subjects worked in 43 different schools located in 33 rural communities throughout the province.

The 5 cohorts consisted of 68 female and 18 males in their final year of the Bachelor of Education program. Each year's cohort was representative of the population of the approximately 400 interns completing their pre-service extended practicum program, with respect to: the variety of grade levels and subjects taught; the mix of their major and minor teaching specializations; and the range of student enrolments in the schools in which they served. Likewise, the cooperating teacher sub-group of each of the five cohorts represented a similar cross-section of experienced teachers in the province's schools.

Further demographic data indicate that approximately $60 \%$ of the interns participating had previously lived in a rural area prior to their rural-based extended practicum, while for most of the other $40 \%$, the 16 -week internship was their first experience living in a rural location for a lengthy period. It should also be noted, moreover, that approximately $60 \%$ of the 86 interns had previously completed a two-week student-teaching period (i.e., the "pre-internship" schoolbased experience) in a rural setting several months earlier. (However, only 20\% of this pre-internship sub-group actually moved to the rural location, because these shorter practicum placements are arranged by the University in schools within one-hour driving distance from the city. Hence, for the pre-internship practicum, the majority of student teachers retained their urban accommodations and commuted daily to and from the rural schools.)

With respect to the cooperating teachers in the study, all of them had resided in the rural locations for at least two years, while $75 \%$ of them also had previous teaching experience in urban schools. Thus, virtually all of the subjects had 
experienced teaching or living in both urban and rural areas, therefore having a basis for comparing one with the other.

\section{Procedure}

For each of the five cohorts during the fourteenth week of the 4-month practicum, I had the pairs complete a written survey that consisted of four openended questions: (a) What do you see as advantageous about completing their internship (and for the cooperating teachers, "teaching”) in a rural school? (b) What has been disadvantageous? (c) Would you recommend that future interns do their extended practicum in rural or urban schools? and (d) What one item of advice would you give new interns (or teachers) regarding that choice?

The overall response rate for interns was $96 \%$ for the written questionnaires, and for the cooperating teachers it was 92\%. (For the latter, one cohort was not surveyed.)

I collated and analyzed their written responses using the "constant comparative" technique (Glanz, 1998), in which an inductive analysis of the data was conducted (Best \& Kahn, 1998). Using this approach, I engaged in a process of systematically categorizing and re-categorizing the responses, according to emerging patterns, categories, or themes from the data. These evolving categories gradually formed a framework for communicating the essence of how the teacher-interns and their cooperating teachers perceived their practicum experiences (McMillan \& Schumacher, 2001).

In order to help verify the validity of these data, I incorporated a triangulation procedure, in which I compared the survey results with data derived from four other relevant sources (Hittleman \& Simon, 1997). Triangulation is an accepted analytical technique to enhance the trustworthiness and credibility of a qualitative study (McMillan, 2000). It uses different methods of data gathering for the purpose of comparing the findings derived from these multiple approaches (McMillan \& Schumacher, 2001) or of obtaining similar information from different independent sources (Gay \& Airasian, 2000). The additional sources I used in the present study were: (a) the oral comments I noted among interns and teachers during supervisory post-conferences and in informal conversations with the author at the pairs' respective schools; (b) my regular observations of, and participation in, casual conversations between/among several interns and/or cooperating teachers that occurred at the three internship in-services, at the schools, and at the in-service lunch times; (c) data I collected from the 2001 and 2002 cohorts in response to the question, "What could the University and the rural school divisions do to improve interning (and teaching) in rural schools?’(Ralph, 2002); and (d) previous related research (Borys et al. 1991; Meiklejohn \& Barrett, 1994; Ralph, 1994-1995, 1995; Ralph \& Yang, 1993). I anticipated that the categories and patterns that I identified in the pairs' survey results would be similar to those found in the above four sources-thereby increasing the believability and plausibility of this study's results.

I summarized these data in tabular format, as described in the following section. 


\section{Findings and Discussion}

Advantages of Teaching in Rural Schools

The values in Table 1 (i.e., the numbers of respondents and corresponding percentages for each category) summarize the views of the five cohorts of interns and their cooperating teachers in rural schools (in 1998 there were 23 pairs; in 1999 there were 13 pairs; in 2000, 19 pairs; in 2001, 12 pairs; and in 2002, 18 pairs).

\section{Table 1}

Summary of Interns' and Cooperating Teachers' Responses Identifying Advantages of Interning or Teaching in Rural Schools ( $\underline{N}=85$ for interns; $\underline{N}=71$ for cooperating teachers)

\section{Advantages}

1. Better acquaintance with students

2. High community involvement

3. Support by staff and community

4. Better acquaintance with families

5. Opportunity to engage in variety of activities

6. Lower enrolments

7. A "countryside" pastoral setting

8. Fewer student discipline problems

9. Opportunity to secure a rural teaching position
Interns \% (Number)

67 (57)

$55(47)$

$53(45)$

20 (17)

$16(14)$

$16(14)$

$12(10)$

4 (3)
Teachers \% (Number)

65 (46)

Note. Values represent percentage of respondents in each sub-group, who identified advantages in their written comments. The numerals in parentheses are the number of respondents. (Values are rounded.)

An examination of Table 1 shows that the sub-groups of interns and cooperating teachers were in general agreement with respect to nine benefits of rural teaching

For six of the nine advantages (i.e., items \#1, \#2, \#3, \#5, \#8, and \#9) relatively similar numbers of interns and cooperating teachers were in agreement. These data suggest that when the respondents (whether novice or veteran) compared their rural educational experiences to their urban ones (either as a student, a student-teacher, or a teacher) they were in accord in ranking the rural aspects higher in specific areas such as: knowing the students better, being more involved in the community, engaging in a wider variety of school-related activities, having fewer student discipline problems, and increasing one's opportunity to subsequently secure a rural teaching position. 
The perception that rural schools have less severe management and discipline problems is in accord with American research that has repeatedly shown that U.S. urban dwellers tend to rank student discipline/fighting/violence/gang conflict as being more problematic in schools than do non-urban dwellers (Rose \& Gallup, 2003). Part of the sample investigated in the present study included schools in Aboriginal communities. Although some respondents from these schools reported experiencing student discipline problems, others did not. For example, near the end of the practicum, one intern from the primary section of a band-controlled school stated to me: "I found that the kids behaved so differently for one teacher than for another... For they were awful, but for they were better... I tried to copy how [the latter] did it, and I found that they behaved for me, too.” Two other interns from First Nations schools (one at the primary level and one in the middle years) expressed similar views. These data therefore suggested that classroom management effectiveness in First Nations schools appeared to depend as much on the individual teacher within her/his specific classroom context, as on the commonly expressed belief that discipline is problematic in all Aboriginal classes (Ralph, 1993).

What distinguishes the six advantages for rural areas, as shown in Table 1, is a function of the phenomenon of "the smaller community". For instance, one cooperating teacher commented: "Not only does everybody know everybody else, but each person has an important role to play to make the whole community run ... ". Another cooperating teacher wrote: "Everyone knows everything about you, but that's okay, because we all have to pitch in and do our part, regardless ... . even though sometimes we get burned out ... .".

An intern remarked: "Compared to the city, where you can become lost at four o'clock and do your own thing 'til nine the next morning, here, you are expected to teach, to coach, to go curling, and to squeeze in attending your students' hockey game, too."

Because of the close-knit community relationship that tends to emerge in rural areas, where people meet both in formal and informal settings, nearly all of the subjects commented that the increased social interaction and community participation promoted knowing the students and their families better, which in turn led to bolstering mutual school-community support, fewer discipline problems, and-- as one intern suggested: “. . . getting to know the school division administrations thereby bettering my chances of being hired next fall."

On the other hand, for three of the nine advantages summarized in Table 1, there was a discrepancy in the number of interns and cooperating teachers identifying each one, namely, item \#4 (better acquaintance with families), item \#6 (lower school/class enrolments), and item \#7 (a relaxed atmosphere). One explanation for these differences in views between teachers and interns is the respective perspectives and unique prior experiences of each sub-group. For instance, $61 \%$ of the teachers (compared to only $20 \%$ of the interns) stated that teachers become better acquainted with the families, probably because the teachers, who had been living in the community for several years, had previously taught the present pupils' brothers and sisters (or occasionally their mothers and fathers). Thus, compared to the interns, who had lived in the particular 
community for only a few weeks, the cooperating teachers were well acquainted with all of the families.

Similarly, with respect to the advantage of lower enrolments (\#6), the cooperating teachers' extended experience (compared to the interns' relatively scant teaching background) allowed the former to compare any of their prior school experiences teaching greater student populations with the current smaller ones. By contrast, the interns, by virtue of their "newness", had little or no teaching background with which to compare the enrolment factor.

Interestingly, for item \#7 more interns (16\%) than cooperating teachers (7\%) relished the "country living" aspect of rural existence, compared to their prior experiences of city life. Another plausible explanation for the variance in responses between the cooperating teachers and interns may be due to the career differences that exist between experienced and novice teachers (Berliner, 1986; Shulman, 1987). The experienced teachers had taught long enough to have witnessed many of these phenomena over a period of years, and thus may take them for granted, while the latter generally had little or no teaching background against which to measure their limited extended practicum experience.

\section{Disadvantages of Teaching in Rural Schools}

The values shown in Table 2 summarize the views of the five cohorts of interns and their cooperating teachers, with respect to the drawbacks of teaching in rural schools.

Table 2

Summary of Interns' and Cooperating Teachers' Responses Identifying Disadvantages of Interning or Teaching in Rural Schools $(\underline{N}=85$ for interns; $\underline{N}=71$ for cooperating teachers)

\section{Disadvantages Interns \% (Number)}

1. Lack of professional resources/services

2. Invasion of privacy

3. Work overload (split grades, extra-curricular duties)

4. Greater expense (accommodation, travel, etc.)

5. Isolation from support groups (family, friends)

6. Inadequate living accommodation

7. Lack of diversity in school or community

8. Feeling “distanced” from staff/peers
$66(56)$
Teachers \% (Number)

64 (45) written comments. Numerals in parentheses are number of respondents. (Values are rounded.) 
As was the case for the data shown in Table 1, both sub-groups shared corresponding views; however, only 4 of the 8 disadvantages had similar numbers of responses by both subgroups. These disadvantages were: \#1, a lack of professional resources and services (e.g., "We have to drive 45 minutes to get to the nearest McDonalds”); \#2, a lack of personal and/or family privacy (e.g., "You really do live in a fishbowl here") ; \#6, a shortage of suitable housing/accommodation; and \#8, a feeling of isolation from peers. A typical comment from interns in category \#8 was: "I had little social life, because I was away from family and friends for a month at a time.”

Although these four categories may not be unique to rural locations, it appears that both sub-groups perceive that living in rural settings does accentuate these drawbacks. On the other hand, teachers living and/or working in urban locales do not typically report these disadvantages.

Of the four disadvantages that show a wider variance between the two subgroups, the interns identified three of them by a much wider margin than did the cooperating teachers. These three items were: \#4, greater expense incurred (for accommodation and travel); \#5, feelings of isolation from family and friends; and \#7, the relative lack of diversity among students and their families.

These findings may be explained by some of the study's demographic data that revealed that: all of the interns had to find accommodation in the rural areas where they taught; they all had to pay University tuition for internship for a full term (they paid for the extended-practicum as a 15 credit unit course); they had to maintain and operate a vehicle in order to travel to and from their permanent home (or their parents' home); and many of them were obligated to pay "double rent" because of having to retain their city accommodation for their return to campus for the "post-internship" term following the extended practicum. For instance, one intern wrote: "I hated having to pay rent in 2 places, plus it is always expensive to move everything to a new location every 4 months (reconnecting utilities, damage deposit, car expenses etc.)"

The two disadvantages of teaching in rural communities identified by the interns (item \#4, the greater expenses incurred, and item \#5, the isolation from family), were mentioned by few cooperating teachers, probably because the latter had become settled residents of their communities and did not have to face these challenges in the same way that the interns did. Also, it is possible that some cooperating teachers may have selectively forgotten their own previous negative experiences of being a newcomer to teaching in a rural location, whereas the interns saw the issues as immediate.

\section{Recommendations of Placement for Rural Internship}

Respondents’ recommendations for placing future interns and/or beginning teachers in rural settings are summarized in Table 3. Although the majority of respondents in the interns' sub-group preferred rural placements, and although very few respondents in both sub-groups recommended solely urban placements for future interns, a substantial number of respondents in both sub-groups suggested that the internship should occur in either rural or urban schools, according to whether or not the intern had previous experience in one or the 
other. More cooperating teachers than interns favoured this "both" category, and their reasons for selecting that option again reflected their unique professional insights, such as: “... they should experience both areas, so they can decide later where to apply...". Other contingencies for this third category were: "The internship should be rural if the student-teaching was urban, and vice-versa"; "Beginning teachers should have experience in both settings"; and "The choice should be left to the individual as to what they need to give them a good balance...".

\section{Table 3}

\section{Summary of Interns' and Cooperating Teachers' Responses Recommending Placements for Future Interns ( $\underline{N}=85$ for interns; $\underline{N}=71$ for cooperating teachers)}

\section{Recommendation}

1. Placement solely in rural schools

2. Placement both in rural and urban schools

3. Placement solely in urban schools
Interns \% (Number)

68 (58)

4 (3)
Teachers \% (Number)

49 (35)

$48(34)$

$1(1)$

Note. Values represent percentage of respondents in each sub-group, who indicated recommendation for future placement of interns. Numerals in parentheses are number of respondents. (Values are rounded.)

As noted above, almost all respondents had some previous educational experience both in rural and urban centres--as teachers or students. The interns' rural teaching experience, however, was much more limited. For some of them, their prior student-teaching session consisted of a limited two- or three-week period in an urban school; for the remainder, it was two or three weeks in a rural school. All of the cooperating teachers and approximately $60 \%$ of the interns had previously attended rural schools as students (or had been on staff as teachers or student-teachers); therefore, almost all of the respondents were at least somewhat familiar with the experience of living in rural and urban communities.

\section{Advice for Future Rural Interns}

Table 4 summarizes the advice offered to future rural interns and beginning teachers by both subgroups. Among the six categories of advice, the first five items were offered jointly by interns and cooperating teachers. These categories were: to become involved; to work conscientiously; to be open to the rural experience; to be forewarned of a lack of privacy; and to develop networks with other teachers. Although these suggestions could apply equally to all teachers in all locations, items \#3 and \#4 are especially appropriate for rural personnel. An example of the cooperating teachers' advice was: "In a smaller centre watch your social activities. These people may judge you quickly, and it would be hard to 
get your respect back." Another teacher advised: "Be prepared to be available to parents 15 hours a day. Impromptu interviews will occur in the grocery store, doctor's office, village office etc. ... Be flexible.”

\section{Table 4}

Summary of Interns' and Cooperating Teachers' Advice for Future Neophytes

Placed in Rural Schools ( $\underline{N}=85$ for interns; $\underline{N}=71$ for teachers)
Advice
Interns \% (Number)
Teachers \% (Number)

1. Become involved in a $35(30)$

variety of school/community activities

2. Be conscientious about teaching activities

3. Be open-minded about the rural placement

4. Be aware of constant public scrutiny

5. Communicate with other new teachers

6. Realize that rural teachers are as "professional” as urban ones

Note. Values represent rounded percentages of respondents from each sub-group, who offered written advice. Numerals in parentheses are number of respondents. (Values are rounded.)

As was the case for the data in the three previous tables, the differences between the teacher interns' and cooperating teachers' views shown in Table 4 were due to individuals' unique situations in their respective contexts. The interns are reacting to the recency of their personal and professional experiences in the extended practicum and student teaching, while the cooperating teachers are representing a broader perspective influenced by several years of professional life in a variety of educational settings. The latter's greater accumulation of experiences and wisdom of practice prompt them to reflect on issues that novices may not have yet even considered (e.g., Item \#6, "to recognize that rural teachers are just as good as urban ones ...” was expressed by two cooperating teachers, but by no interns).

On the other hand, the more seasoned teachers may not share the significance that interns place on elements like \#2 (where twice as many interns as cooperating teachers stressed demonstrating keenness in performing all of their instructional activities). This difference may well be due to the fact that the cooperating teachers tend to take such intern behaviour for granted--in that they assume that all interns would naturally show such dedication. The interns, by 
contrast, feel that specifically advising new interns to attend to this process warrants particular consideration.

\section{Additional Findings}

An analysis of the additional data submitted by the 2001 and 2002 cohorts (with respect to what the University and the rural school divisions could do specifically to improve the interning and teaching process) identified a range of suggestions embodied in six general categories. For the sake of brevity only key results are highlighted below.

\section{Prior procedures}

Respondents suggested that the University should better prepare all interns to meet the unique contexts of rural life (e.g., have them interact with former rural interns or current rural teachers prior to their placements). School divisions were urged to select only those classroom cooperating teachers, who have proven mentorship skills for supervisory duty. (For instance, several respondents expressed that some teachers felt forced by administrators to accept an intern, and that others regularly requested interns “to serve as slave labor.”)

\section{Actual placements}

The University and rural school divisions need to ensure that every intern/cooperating teacher pair is appropriately matched (as to subject area, grade, and interests). For example, four interns believed that some placements were seriously mismatched, but that the interns in these mismatches refrained from reporting the strained relationship for fear of being negatively judged, because their cooperating teachers had considerable power over the student's final evaluation, and possibly their job search for a first teaching position.

\section{Program issues.}

The University and school divisions were encouraged to better coordinate their efforts to make relevant learning materials/resources available to all interns and beginning teachers. An example of the many comments, here, was one by a cooperating teacher: "Provide a listing of all resources available throughout the division, and provide ready access to them so that all teachers and interns could borrow them or have them delivered and picked up by a school van or bus.”

\section{Living accommodations}

Respondents recommended that the College and the rural divisions should collaborate to formulate an updated listing of available accommodations for interns and new teachers in each area. Newcomers will thus be assisted in making the transition into the rural community, and in feeling more welcome. A sample comment from an intern was: "There are many housing opportunities in any small town that an intern will not know about. School Divisions should have someone to help them find these places...”. 


\section{Courses}

The University should not make concurrent coursework mandatory for interns. The extra responsibility of carrying another course (albeit, even for an appropriate topic such as

classroom management), in addition to the considerable load of the extended practicum, is for some interns more of a hindrance than a help. The University should cut the concurrent course and re-allocate the resources to enhancing the existing practicum program, per se.

With respect to the cooperating teachers, two respondents suggested that the University and rural districts should adopt the model used in some other jurisdictions that award graduate course-credit to cooperating teachers who volunteer to mentor teacher-interns.

\section{Financial concerns}

Several respondents urged the University to reduce the total tuition fee amount charged to interns who must move to rural areas; and many also recommended that all rural school divisions re-instate the monthly honorarium (of $\$ 100.00$ to $\$ 200.00$ ) given to interns who select their district for the practicum. In comparison to teachers who earn a salary from the school division, interns incur increased costs because of rural internships. Establishing initiatives to help them defray these expenses would be most welcome. An illustrative comment among many from both sub-groups was: "Money can be one of the biggest stresses an intern can have... . The monthly amount was greatly appreciated, but more would be nice...”.

Although these six suggestions could apply to rural and urban settings alike, items \#4 and \#6(accommodation and financing) are especially pertinent to rural schools. The fact that securing suitable accommodations is more difficult in rural than in urban areas, coupled with the multiplied financial burden for interns to move to, live in, travel to and from their rural placements (and sometimes to maintain dual facilities for the four-month session), all combine to exert increased pressure on interns. These concerns could be addressed and dealt with in a collaborative fashion by all stakeholders.

\section{Implications for Stakeholders}

This study has shown that rural placements for the extended practicum are viewed positively by interns and cooperating teachers, alike. Not surprisingly, interns in rural areas experience all of the concerns that interns anywhere would have to confront; however, the issues that are distinctly rural in nature relate as much to out-of-school factors as to in-school ones, such as securing adequate accommodation and incurring extra expenses. A typical intern comment was: "Reduce the tuition for those placed two hours out of the city . . . or increase the stipend [offered by some rural school divisions] to interns.” Similarly, a common cooperating teacher suggestion was reflected in this written submission: "Pay the interns a monthly honorarium and offer them affordable housing for the term." Also, many interns and cooperating teachers identified the lack of access to 
instructional resources and professional support as problematic in rural areas compared to urban ones.

Several implications for teacher educators and school division personnel may be drawn from all of the insights gained in this study.

First, educational leaders both at the University and in the rural school divisions need to collaborate to maintain the positive aspects of the rural internship as identified by both sub-groups in the study (as shown in Table 1). Despite the fact that rural populations in the province of Saskatchewan are declining - with the consequent reduction in school enrolments-it is noteworthy that rural school divisions still account for approximately $41 \%$ of Saskatchewan's K- 12 student population, $60 \%$ of its schools, and $44 \%$ of its teachers (Saskatchewan Learning, 1998, 2000, 2001, 2002). Since teachers will need to be recruited for these rural areas, it is logical to assume that the University and the rural school divisions must sustain the positive features of the extended practicum experiences in order to attract prospective teachers to rural districts. Furthermore, the University and the school divisions may need to provide additional support in areas they may not have typically viewed as under their jurisdiction, such as considering subsidizing the rural internship.

A second related implication for school divisions and the University is that they would be responsible not only to inform their respective personnel of the perceived drawbacks of rural teaching (as shown in Table 2), but to cooperate at eliminating them. For a specific example, in order to help remedy the lack of availability of instructional resources that both the present study's cohorts and those in previous studies have identified in some rural schools (Ralph, 2000, 2001, 2002; Ralph \& Yang, 1993), the rural school divisions and the University could collaborate in resolving the problem. They could easily (a) implement more productive use of the Internet and e-mail between/among the schools and the University in order to publicize and distribute curricular and instructional resources; (b) sponsor a temporary courier or pick-up-and-delivery service to operate between/among the institutions; or (c) initiate a plan whereby interns, or school staff members, or college supervisors en route to the city, could pickup and/or deliver some of the requested instructional resources. Although universities do not typically provide such services for interns or practicing teachers, perhaps they, as one of the major players in the teacher development process, need to initiate such a strategy in order to invite other stakeholders such as the provincial departments of education and the teachers' unions to collaborate in assisting novice teachers as they navigate the critical period of their induction into the teaching profession (Ralph, 1994).

In addition, during the regular orientation sessions conducted for interns and cooperating teachers at the beginning of the extended practicum program, specific strategies could be considered for addressing recurrent issues related to the rural internship. For instance, with respect to the extra expenses incurred by the interns in rural areas, the practicum stakeholders could jointly recommend that a payment by rural school divisions to interns of a monthly stipend (e.g. $\$ 100.00$ or $\$ 150.00$ ) be re-instituted. (This previously successful remuneration plan was unfortunately discontinued by several school divisions in the Province a 
few years ago, when provincial government funding to school districts was reduced. However, only a few rural divisions have re-implemented this initiative).

Furthermore, to address the problem raised by some respondents related to the securing of adequate living accommodation in some rural communities, renewed efforts by the school principal and the staff to alert the whole community of this need each year (via posters or mailouts) could help alleviate this problem. Rural residents would also benefit financially and socially by contributing to the life of the school and the community through their provision of rental accommodation for the interns and/or new staff members.

Also, to address the concern expressed by some interns and novice teachers in rural schools with respect to feeling isolated from the staff, all school personnel could be encouraged to welcome the neophytes by offering personal and professional support and encouragement, particularly at the early stages of their placements. Although all novice teachers, including those in large urban schools, may experience such feelings, rural beginning teachers may have more difficulty, because they may feel this isolation in the community, as well. Nevertheless, the welcoming and supportive strategies that have been identified in previous research, have proven to be mutually beneficial to all stakeholders in the practicum program (Borys et al. 1991).

\section{Other Jurisdictions}

A limitation common to qualitative research is the lack of generalizability to other situations (Hittleman \& Simon, 1997). However, as recognized by many research experts in the social sciences (Best \& Kahn, 1998; Glanz, 1998), this "generalization caution" could be re-framed in a more helpful manner. For instance, other universities and school divisions seeking to improve the operation of their particular practicum programs could examine this present study in order to inform their respective policies and practices. Therefore, a key objective of the present study was to generate what Eisner (1998) specifies as: "Generalizations . .. as tentative guides, as ideas to be considered, not as prescriptions to follow" (p. 209).

Thus, the "ideas to be considered" from the present findings do affirm the positive contribution made by rural schools toward the professional growth of prospective teachers. As stakeholders continue to collaborate in enhancing the quality of rural teaching, it is hoped that they will he able to agree with one experienced teacher in this study who advised: "I recommend a rural internship because what interns learn there will better prepare them for the majority of teaching opportunities anywhere-rural or urban.”

\section{References}

Berliner, D. (1986). In pursuit of the expert pedagogue. Educational Researcher, 15(7), 5-13. Best, J., \& Kahn, J. (1998). Research in education ( $8^{\text {th }}$ ed.). Boston: Allyn and Bacon. 
Borys, A., Wilgosh, L., Lefebvre, V. Kiselvich, B., Samiroden, W., Olson, A., \& Ware, R. (1991). An alternative model for rural pre-service practicum supervision. Education Canada, 31(4), 47.

Eisner, E. (1998). The Enlightened Eye. Columbus, OH: Merrill.

Fuller, F., \& Bown, D. (1975). Becoming a teacher. In K. Ryan (Ed.), Teacher education: The $74^{\text {th }}$ Yearbook for the National Society for the Study of Education (Part II, pp. 25-52). Chicago: University of Chicago Press.

Gay, L., \& Airasian, P. (2000). Educational Research: Competencies for Analysis and Application ( $6^{\text {th }}$ ed.). Columbus, OH: Merrill.

Glanz, J. (1998). Action Research: An Educational Leader's Guide to School Improvement. Norwood, MA: Christopher-Gordon.

Government encourages boards to pare numbers. (2001, December 10). Saskatchewan Teachers Federation Bulletin, 68(5), 1-5.

Hemmings, B., \& Boylan, C. (1992). Lessons for the future: A remote rural practice teaching program. Education in Rural Australia, 5(2), 25-32.

Hittleman, D., \& Simon, J. (1997). Interpreting Educational Research: An Introduction for Consumers of Research (2th ed.). Columbus, OH: Merrill.

Howey, K., \& Zimpher, N. (1989). Profiles of Pre-service Teacher Education: Inquiry into the Nature of Programs. Albany, NY: State University of New York Press.

Howley, C. (1997). How to make rural education research rural: An essay at practical advice. Journal of Research in Rural Education, 13(2), 131-138.

Khattri, N., Riley, K., \& Kane, M. (1997). Students at risk in poor rural areas: A review of the research. Journal of Research in Rural Education, 13(2), 79-100.

McMillan, J. (2000). Educational Research: Fundamentals for the consumer ( $3^{\text {rd }}$ ed.). New York: Longman.

McMillan, J., \& Schumacher, S. (2001). Research in Education: A Conceptual Introduction (5th ed.). New York: Longman.

Meiklejohn, K., \& Barrett, E. (1994). Isolated schools project. Education in Rural Australia, 4(2), 31-32.

Piland, D., \& Anglin, J. (1993). It is only a stage they are going through: The development of student teachers. Action in Teacher Education, 15(3), 19-26.

Ralph, E. (1993). Enhancing Aboriginal teacher education: One promising approach. Canadian Journal of Native Education, 20 (1), 44-62.

Ralph, E. (1994). Enhancing the supervision of beginning teachers: A Canadian initiative. Teaching \& Teacher Education, 10 (2), 185-203.

Ralph, E. (1994-1995). Towards renewal in the practicum: Insights from one college's journey. Journal of Professional Studies, 2(1), 3 7-44.

Ralph, E. (2000). Teacher-interns in rural schools. Brock Education, 10(2), 73-90.

Ralph, E. (2001, April). Teaching in rural schools: A synthesis of interns' and cooperating teachers' views. Proceedings of the Sixth National Congress on Rural Education: The Rural School A Partner in Community Progress, The Centre of Learning (pp. 1-17). Saskatoon, Saskatchewan, Canada: University of Saskatchewan, College of Education, Saskatchewan Educational Leadership Unit.

Ralph, E. (2002). Addressing interns' concerns during the extended-practicum. Journal of the International Society for Teacher Education, 6 (2), 37-48.

Ralph, E., \& Yang, B. (1993). Beginning teachers' utilization of instructional media: A Canadian case study. Educational \& Training Technology International, 30 (4), 299-318.

Rose, L., \& Gallup, A. (2003). Urban dwellers on urban schools. Phi Delta Kappan, 84 (5), 408409.

Saskatchewan Educational Leadership Unit. (2003, April). Eighth National Congress on Rural Education: Designing Our Future...Making the Right Decisions (Proceedings). Saskatoon, Saskatchewan: University of Saskatchewan, Department of Educational Administration. 
Saskatchewan Learning. (1998). Summary: Enrolment Statistics. Regina, Saskatchewan: Saskatchewan Book Bureau.

Saskatchewan Learning. (2000). Saskatchewan Indicators: Kindergarten to Grade 12. Regina, Saskatchewan: Author.

Saskatchewan Learning. (2001). Saskatchewan Indicators: Kindergarten to Grade 12. Regina, Saskatchewan: Author.

Saskatchewan Learning. (2002). Saskatchewan Indicators: Kindergarten to Grade 12. Regina, Saskatchewan: Author.

Shulman, L. (1987). Knowledge and teaching: Foundations of the new reform. Harvard Educational Review, 57, 1-22.

Smith, D., \& Sanche, R. (1992). Saskatchewan interns' concerns at three stages of a four-month practicum. The Alberta Journal of Educational Research, 38(2), 121-132.

Smith, D., \& Sanche, R. (1993). Interns' personally expressed concerns: A need to extend the Fuller model? Action in Teacher Education, 15(1), 36-41.

Wilson, B., Ireton, E., \& Wood, J. (1997). Beginning teacher fears. Education, 117(3), 380, 396402. 